\title{
A EDIÇÃO DE ARTIGOS CIENTÍFICOS NA DIVISÃO DE PERIÓDICOS DO CEGRAF/UFG: CONCEITO, PROCESSO E GERENCIAMENTO
}

Janaynne Carvalho do Amaral ${ }^{1}$

\author{
Como citar: \\ AMARAL, J. C. A edição de artigos científicos na divisão de periódicos do cegraf/ufg: conceito, processo e \\ gerenciamento. In: ABEC MEETING, 1, 2017, Curitiba. Anais... Curitiba: Associação Brasileira de Editores \\ Científicos, 2017. p. 80-85. \\ http://dx.doi.org/10.21452/abecmeeting.2017.014
}

\begin{abstract}
Resumo: Este trabalho apresenta o conceito de revisão, o processo de edição de texto e as estratégias de gerenciamento das propostas de correção, adotados e criados pela seção de revisão da Divisão de Periódicos do Centro Editorial e Gráfico da Universidade Federal de Goiás (CEGRAF/UFG). Fundado em 2015, o departamento é responsável pela revisão de textos, normalização, tradução e diagramação dos periódicos subsidiados pelo Programa de Apoio às Publicações Periódicas Científicas (PROAPUPEC/UFG). A metodologia usada consistiu no acesso e consulta aos Protocolos e documentos da Divisão de Periódicos publicados na página do CEGRAF/UFG. Concluiu-se que, embora o conceito de edição de texto do departamento seja o mesmo desde a sua criação, os processos de revisão e as estratégias de gerenciamento das propostas de revisão estão em constante transformação. Simultaneamente, ressalta-se o potencial educativo e de suporte ao editor e ao autor dos departamentos de periódicos situados em editoras universitárias.
\end{abstract}

Palavras-chave: Edição de texto. Artigo científico. Divisão de Periódicos da UFG.

\begin{abstract}
This paper presents the concept of revision, the text editing process and the management strategies of the correction proposals, adopted and created by the review section of the Divisão de Periódicos of Centro Editorial e Gráfico of Universidade Federal de Goiás (CEGRAF/UFG). Founded in 2015, the department is responsible for proofreading, ABNT standardization, translation and diagramation of scientific journals subsidized by the Programa de Apoio às Publicações Periódicas Científicas (PROAPUPEC/UFG). The methodology used consisted of access to and consultation of the Protocols and documents of the Division of Periodicals published on the CEGRAF website. It was concluded that, although the department's concept of text editing has been the same since its inception, the text editing process and the management strategies of the correction proposals are constantly changing. We suppose that the success of implementing each procedure depends on the quality of communication between text editors, journal editors, and authors. At the same time, the educational and support potential of the editor and author of the departments of periodicals located in university publishing houses.
\end{abstract}

Keywords: Text editing. Scientific article. Divisão de Periódicos da UFG.

\section{INTRODUÇÃO}

Segundo Araújo (2008, p. 59, grifo do autor), "Editar sempre envolve, em alguma medida, 'mexer' no texto alheio." E, "na área da publicação, o editor de texto definiu-se primordialmente como normalizador de originais, vale dizer, como o profissional encarregado de conferir uniformidade global ao texto [...]" (ARAÚJO, 2008, p. 55, grifo do autor). O autor explica que certos tipos de textos necessitam de uma normalização especial; e como exemplo, Araújo (2008) cita os textos teatrais e em escritos em versos (poesia), nos quais "a liberdade de criação do autor tem de ser respeitada" (p. 143). A redação científica também tem as próprias características, conforme Barradas e Targino (2008, p. 21), "[...] a subjetividade caracteriza o estilo literário, em sua construção e interpretação; e a objetividade, o estilo científico." Para as autoras, são características da redação técnico-científica, a clareza na expressão de ideias, o uso de palavras precisas e adequadas segundo a terminologia de cada área, simplicidade, objetividade, concisão e coesão, sequência lógica na apresentação de sentenças, capacidade argumentativa, fidelidade às fontes. Meadows (1999, p. 122), 
acrescenta, ainda, que "Todas as áreas especializadas desenvolvem seus próprios vocabulários".

Os periódicos podem ser vistos como a ferramenta mais importante para a divulgação de resultados de pesquisas e experiências (BIOJONE, 2003). E

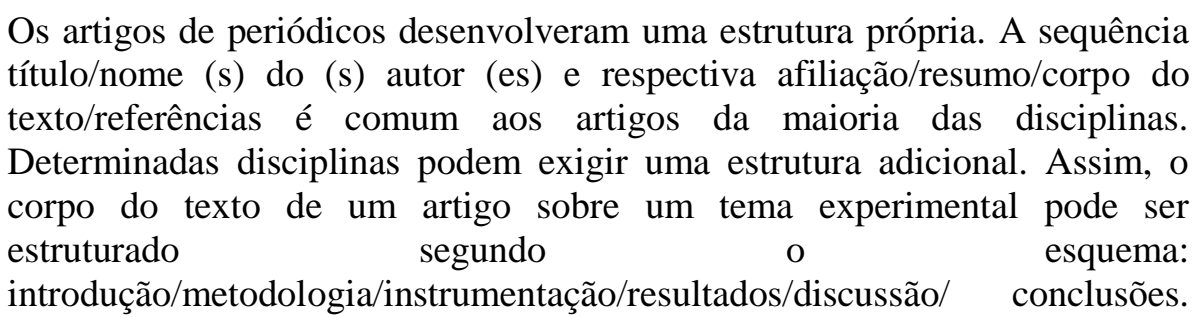
(MEADOWS, 1999, p. 119).

Compreender as particularidades da redação científica, a estrutura do artigo científico e as normas de publicação de um periódico, é fundamental tanto para o autor que deseja compartilhar os resultados de sua pesquisa quanto para quem edita um texto científico. Neste sentido, fundada em 2015, a Divisão de Periódicos do Centro Editorial e Gráfico da Universidade Federal de Goiás (CEGRAF/UFG) é responsável pela revisão de textos (português, inglês e espanhol), normalização, tradução (inglês e espanhol) e diagramação dos periódicos subsidiados pelo Programa de Apoio às Publicações Periódicas Científicas (PROAPUPEC/UFG) (AUTOR, 2016). Desta forma, o objetivo deste trabalho é apresentar o conceito de revisão, o processo de edição e as estratégias de gerenciamento das propostas de correção, adotados e criados pela seção de revisão da Divisão de Periódicos da UFG, composta por bolsistas, para editoração dos periódicos apoiados pelo PROAPUPEC/UFG. Espera-se que o relato dessas experiências possa contribuir para o diálogo e desenvolvimento de outras seções de periódicos que estão surgindo no Brasil, em decorrência dos editais de apoio à publicação de periódicos elaborados por universidades que selecionam alunos de graduação e pós-graduação para atuarem como bolsistas na edição de periódicos institucionais. Entre elas, cito a Universidade Federal do Paraná.

\section{METODOLOGIA}

Consiste no acesso e consulta aos Protocolos e documentos da Divisão de Periódicos publicados na página do CEGRAF/UFG ${ }^{1}$, tais como os Protocolos da Divisão de Periódicos da UFG (CEGRAF/UFG) (2015a, 2015b, 2017), a Relação de Solicitações da "Seção de Revisão" da "Divisão de Periódicos da UFG" (CEGRAF/ UFG) aos (às) editores (as) das revistas (2016a) e, também, os documentos Divisão de Periódicos da UFG (CEGRAF/ UFG) -

\footnotetext{
${ }^{1}$ Disponível em: < https://www.cegraf.ufg.br/p/7275-protocolos $>$. Acesso em: 18 out. 2017.
} 
AMARAL, J. C.

"A edição de artigos científicos na divisão de periódicos do cegraf/ufg: conceito, processo e gerenciamento"

Orientações para Apresentação de Referências (2016b) e o Tutorial para o feedback dos/as autores/as.

\section{RESULTADOS E DISCUSSÃO}

O primeiro Protocolo da Divisão de Periódicos da UFG (CEGRAF/UFG) ${ }^{2}$ foi publicado em 13 de abril de 2015, e ao esclarecer para o editor o nível de qualidade do texto a ser enviado para revisão e o papel dos editores de texto da Divisão, explicitava o conceito de revisão do departamento:

a) $\mathrm{O}$ (a) editor(a) da cada periódico responsabilizar-se-á de enviar, à Divisão de Periódicos, artigos com uma elementar correção gramatical.

b) $\mathrm{O}$ (a) editor(a) da cada periódico responsabilizar-se-á de enviar, à Divisão de Periódicos, os artigos com os conteúdos já verificados. Não cabe aos (às) revisores(as) verificar a correção de teorias, análises, observações, mapas, fórmulas etc.

Tal concepção de revisão alinha-se com o que propõe Araújo (2008). De acordo com o autor, o editor de texto, como preparador de originais, deve considerar que o autor elabora um texto de qualidade do ponto de vista gramatical e informativo, mas mesmo assim, pode faltar a esse texto unidade quanto ao uso de sinais de pontuação, sinais diacríticos, uso de maiúsculas e de abreviaturas e siglas, dentre outras coisas. Assim, para ele, surge o grande dilema da atuação do editor de texto: "qual o seu justo limite para proceder a alterações num escrito de outrem"? (ARAÚJO, 2008, p. 56). Para ele, "[...] a normalização última do texto, desde que não altere seu conteúdo, não só caberá ao preparador de originais como até deverá ser aceita de bom grado pelo autor." (p. 56).

Após seis meses de criação da Divisão de Periódicos, a equipe de bolsistas do departamento elaborou o Protocolo Complementar da Divisão de Periódicos da UFG $(\mathrm{CEGRAF} / \mathrm{UFG})^{3}$. Nele, o conceito de revisão continuou o mesmo. Contudo, nota-se que do primeiro protocolo de 2015 para o segundo alterou-se o processo de envio dos artigos à Divisão: inicialmente, o editor poderia encaminhar os arquivos no formato Word em pacotes compostos por cinco artigos ou todos os artigos de uma única vez e, posteriormente, a revisão só seria iniciada mediante o recebimento de todos os artigos do número em questão.

\footnotetext{
${ }^{2}$ UNIVERSIDADE FEDERAL DE GOIÁS. Centro Editorial e Gráfico. Divisão de Periódicos da UFG. Edital PROAPUPEC - SiBi/ UFG; PRPG/ UFG. Protocolo da Divisão de Periódicos da UFG (CEGRAF/UFG), 2015a. Disponível em: < https://www.cegraf.ufg.br/up/688/o/protocolo div_periodicos..pdf >. Acesso em: 18 out. 2017. 3 _. Centro Editorial e Gráfico. Divisão de Periódicos da UFG. Edital PROAPUPEC - SiBi/ UFG; PRPG/ UFG. Protocolo Complementar da Divisão de Periódicos da UFG (CEGRAF/UFG), 2015b. Disponível em: < https://www.cegraf.ufg.br/up/688/o/protocolo_comp.pdf>. Acesso em: 18 out. 2017.
} 
O processo de edição é executado, segundo o último Protocolo da Divisão ${ }^{4}$, publicado aos 23 de março de 2017, da seguinte maneira: "As edições realizadas pela Divisão de Periódicos embasadas em gramáticas, dicionários e manuais de normalização serão mantidas, mesmo que o/a autor/a discorde." Sendo que ainda consulta-se o editor da revista para a decisão de manter ou excluir uma edição que o autor não esteja de acordo. Quanto à normalização dos artigos, o Protocolo Complementar da Divisão explica que "As revistas que adotam as normas da ABNT devem orientar formalmente os autores (as) a utilizar os padrões da ABNT NBR 6023 para referências e NBR 10520 para citações". Para dar suporte ao processo de padronização editorial dos artigos, a equipe elaborou o documento "Orientações para Apresentação de Referências"5 para os editores, segundo a NBR 6023/2002.

No que se refere às estratégias de gerenciamento das propostas de correção para os artigos dos autores, enviadas pelo editor por e-mail ou pelo Sistema Eletrônico de Editoração de Revistas (SEER), observou-se uma evolução nos procedimentos adotados pela Divisão de Periódicos desde a sua criação. Inicialmente, as propostas eram enviadas para apreciação do autor em formato Word; agora, são convertidas em PDF. Decisão assim justificada na Relação de solicitações da "Seção de Revisão" da "Divisão de Periódicos da UFG" (CEGRAF/ UFG) aos(às) editores(as) das revistas ${ }^{6}$, publicada em 04 de fevereiro de 2016, na página do CEGRAF/UFG,

b) A Divisão encaminhará, ao(à) editor(a), as propostas de revisão em formato PDF para evitar que, pelo fato de se usar diversas versões de Word, algumas palavras apareçam coladas/ emendadas. Dessa forma, o procedimento para aceite ou recusa das revisões deverá ser feito no próprio PDF. Caso o(a) autor(a) não concordar com alguma indicação de revisão, ele deverá registrar o correspondente comentário no próprio documento em PDF.

O item "b", de o Protocolo Complementar da Divisão de Periódicos da UFG, " [...] Caso hajam alterações significativas no conteúdo já enviado para a Divisão de Periódicos, a contagem dos prazos será reiniciada", somado ao item "c": "O acréscimo de parágrafos, frases ou mesmo palavras só será feito nesta etapa de análise das revisões [...]", revela que mesmo após os artigos passarem pela revisão por pares e pela revisão linguística, os autores ainda

4 _. Centro Editorial e Gráfico. Divisão de Periódicos da UFG. Protocolo da Divisão de Periódicos da UFG (CEGRAF/UFG),2017. Disponível em: 〈https://www.cegraf.ufg.br/up/688/o/prot_2017_final.pdf>. Acesso em: 18 out. 2017.

5 _. Centro Editorial e Gráfico. Divisão de Periódicos da UFG. Divisão de periódicos da UFG (CEGRAF/ UFG - Orientações para Apresentação de Referências, 2016b. Disponível em: < https://www.cegraf.ufg.br/up/688/o/apresentacao_ref_2016.pdf >. Acesso em: 18 out. 2017.

6 _. Centro Editorial e Gráfico. Divisão de Periódicos da UFG. Relação de Solicitações da "Seção de Revisão" da "Divisão de Periódicos da UFG" (CEGRAF/ UFG) aos(às) editores(as) das revistas, $2016 a$. Disponível em: https://www.cegraf.ufg.br/up/688/o/solicitacoes_periodicos.pdf>. Acesso em: 18 out. 2017. 
fazem edições nos seus textos. E o arquivo em formato PDF foi o método encontrado para o gerenciamento e controle de qualquer inclusão, exclusão ou alteração de informação no artigo. Para esclarecer os tipos de revisão realizada pela equipe da Divisão de Periódicos e orientar o procedimento para aceite ou recusa das correções no arquivo em PDF, foi criado o Tutorial para o feedback dos Autores ${ }^{7}$. Os editores são orientados a enviarem o Tutorial aos autores juntamente com as propostas de revisão de cada artigo.

E, por último, a versão final de cada artigo, a ser disponibilizada para diagramação, é produzida com base no parecer do autor sobre a revisão. A finalização da edição de texto acontece quando o artigo é armazenado, com todas as correções devidamente realizadas e aceitas, na pasta "Finais, da Divisão de Periódicos, ou no SEER, concluindo a tarefa do editor de texto.

\section{CONCLUSÃO}

O conceito de revisão, bem como todo o processo de edição do texto e as estratégias de gerenciamento das propostas de correção para os artigos científicos, exceto a dinâmica interna da divisão de trabalho entre os revisores. Nota-se que a adoção do formato PDF para o envio das propostas de revisão, permitiu que a seção de revisão alcançasse maior controle sobre a revisão. Todavia, muitos autores têm resistência em deixar comentários no PDF e não respondem aos comentários dos revisores, o que pode ser observado em dois itens do último Protocolo da Divisão (2017): "e) Não serão aceitos novos arquivos elaborados pelos/as autores/as com base em nossa revisão. [...]" e:

Caso o/a autor/a não responda às perguntas feitas em comentários pela equipe, a Divisão não se responsabilizará pela omissão de dados solicitados após a primeira revisão, tais como referências incompletas, parágrafos ou sentenças inconclusas ou incoerentes.

Concluí-se que, embora o conceito de edição de texto da Divisão de Periódicos da UFG seja o mesmo desde a fundação do departamento, os processos de revisão e metodologias de gerenciamento dos originais estão em constante transformação. Supõe-se que o sucesso de implementação de cada procedimento depende da qualidade da comunicação entre editores de textos, editores dos periódicos e autores, e de uma melhor divulgação dos Protocolos da Divisão. O recebimento de artigos científicos com referências incompletas pode refletir tanto a falta de conhecimento do autor sobre normalização quanto à necessidade da

\footnotetext{
${ }^{7}$ Disponível em: < https://www.cegraf.ufg.br/up/688/o/prot_2017 tutorial.pdf>. Acesso em: 18 out. 2017.
} 
disponibilização de Instruções aos autores, mais completas pelos periódicos. Nesse aspecto, ressalta-se o potencial educativo e de suporte ao editor e ao autor dos departamentos de periódicos situados em editoras universitárias.

\section{REFERÊNCIAS}

ARAÚJO, Emanuel. A construção do livro: princípios da técnica de editoração. 2. Ed. Rio de Janeiro: Lexikon, 2008.

BARRADAS, Maria Mércia; TARGINO, M. das G. Redação de artigo técnico-científico: a pesquisa transformada em texto. Mais sobre revistas científicas: em foco a gestão. São Paulo: Senac São Paulo/Cengage Learnig, p. 17-39, 2008.

BIOJONE, M. R. Os periódicos científicos. In: . Os periódicos científicos na comunicação da ciência. São Paulo: Educ; Fapesp, 2003. p. 37-43.

MEADOWS, Arthur Jack; DE LEMOS LEMOS, Antonio Agenor Briquet. A comunicação científica. Briquet de Lemos/livros, 1999. 